\title{
El Estado del lado de lo bueno y de lo malo de las cosas. Apuntes desde la filosofía política para pensar la ocupación de los agentes estatales en la intervención social
}

The State on the side of good and bad things. Notes from the political philosophy to think the occupation of the state agents in the social intervention

O Estado do lado das coisas boas e das coisas ruins. Notas sob a perspectiva da filosofia política para pensar a ocupação dos agentes estatais na intervenção social

Santiago Zorrilla de San Martín*

\section{RESUMEN}

A partir de textos clásicos de la filosofía política, se problematiza las formas de habitar/ocupar el Estado por parte de los agentes técnicos encargados de la intervención social. Conceptualmente, el Estado es colocado tanto del lado de lo bueno como de lo malo de las cosas, de ahí que se vincule la intervención social dirigida tanto a la integración social como a la subordinación. Una vez conscientes de esta discusión, cabe la pregunta acerca de cuánta confianza pueden tener los agentes de la intervención social al Estado y a la función que les demanda cumplir. El eje de la argumentación se apoya en el sugerente libro de Abad y Cantarelli (2010) Habitar el Estado como puntapié para contraponer a Hobbes y Hegel, y sus argumentos a favor del Estado, con la mirada marxista del Estado como esfera de dominación y las posibilidades de superarlo.

\section{SUMMARY}

If we base ourselves on classic political philosophy texts, we see difficulties in inhabiting/occupying the State by technical agents
Palabras

clave: filosofía política, estado, intervención social, trabajo social.

Key words: political philosophy, state,

\footnotetext{
* Uruguayo. Magíster en Trabajo Social, Universidad de la República. Académico Universidad de la República. zorrillasan@gmail.com
} 
in charge of social intervention. Conceptually, the State is placed on both the good and bad sides of things, hence linking social intervention aimed at social integration and subordination. Once aware of this discussion, the question arises as to how much confidence the agents of social intervention can have in the State and the function it demands of them. The axis of the argument is based on the suggestive book by Abad and Cantarelli (2010), Inhabiting the State. Contrasting Hobbes and Hegel, who favor the State and have the Marxist view of the State as a sphere of domination and the possibilities of overcoming it.

\section{RESUMO}

A partir de textos clássicos da filosofia política, são problematizadas as formas de habitar/ocupar o Estado por parte dos agentes técnicos encarregados da intervenção social. Conceitualmente, o Estado é colocado tanto do lado das coisas boas quanto das coisas ruins, daí que a intervenção social dirigida seja vinculada tanto à integração social quanto à subordinação. Quando conscientes desta discussão, cabe perguntar quanta confiança os agentes da intervenção social podem ter no Estado e na função que lhes demanda cumprir. O eixo da argumentação se apoia no sugestivo livro de Abad e Cantarelli (2010) Habitar el Estado como pontapé para contrapor Hobbes e Hegel, e seus argumentos a favor do Estado, com a perspectiva marxista do Estado como esfera de dominação e as possibilidades de superá-lo. social intervention, social work.

Palavraschave: filosofia política, estado, intervenção social, trabalho social. 
Los Estados modernos se fundaron sobre las ideas de libertad e igualdad garantizadas por los derechos civiles y políticos. Sin embargo, tempranamente se vieron enfrentados a los conflictos surgidos por el no cumplimiento de las promesas de seguridad y libertad que garantizarían esos derechos, en particular, derivados de una contradicción entre un orden político que promueve la igualdad y un orden económico que genera desigualdad. La conflictividad derivada de esta contradicción tuvo como consecuencia el nacimiento de la cuestión social. Estudiando el caso francés, Donzelot (2007) identifica la revolución de 1848 como momento significativo en la invención de los social, al instalarse el voto universal (masculino) y el derecho al trabajo. A partir de ese momento, lo social se va a constituir como una esfera que, por medio de la negociación y la solidaridad (en el sentido de Durkheim), va a interceder e interrelacionar entre lo político y lo económico, en busca de evitar que la pobreza y conflictividad derivada del desarrollo del capitalismo termine por quebrantar el orden político y económico. El Estado ya no va a ser solo un Estado político, también se desarrollará como un Estado social que, por medio de políticas sociales, generará lo que Castel (2003) va a denominar la "propiedad social", garantizando la seguridad de los no propietarios. La propiedad social genera una base para que la negociación entre quienes no tienen más que su fuerza de trabajo para vender y quienes tienen capital sea menos usurera, debido a la necesidad de unos con relación a otros. Además de brindar asistencia, así sea mínima, a quienes no encuentran lugar para vender su fuerza de trabajo. La intervención en lo social trabaja sobre la integración, a partir de zurcir el lazo social que mantiene vinculados a los sectores menos favorecidos en el mercado laboral y que, de alguna manera, se pueden volver fuente de conflicto frente a la desintegración social.

Al Estado también se lo puede considerar como un espacio institucional que, en nombre de la representación universal, produce y reproduce desigualdades. Al diferenciar legítimamente a la población por medio de sus categorías administrativas, así como según cada política social (criterios de selección, necesidades a atender, formas de hacerlo, alcance de las prestaciones, entre otras), vuelve socialmente reconocibles las desigualdades sociales subyacentes a esos criterios, instalándolas en lo normal de las cosas. Y en esa natural diferenciación se establecen jerarquías de necesidades e, incluso, qué tipo corresponde atender y cuáles no. 
Ya sea que se haga énfasis en la integración social o en la reproducción de la desigualdad social, ambas miradas no son excluyentes, en tanto que la integración puede ser, y de hecho en general lo es, una integración en la subordinación. Por lo tanto, se entiende que integración y subordinación son dos componentes en la función socializadora del Estado y que se deben poder observar en las prácticas de los agentes que ocupan las diferentes reparticiones burocráticas, lo que incluye la intervención social desarrollada desde las políticas sociales. De aquí que resulte interesante observar el tipo de intervención social que se dirige hacia la población que no encuentra mercado dónde vender su fuerza de trabajo, al menos no un mercado formal y protegido por la propiedad social porque, en nuestros Estados modernos y capitalistas, la intervención en lo social tiene como fundamento que todo el mundo trabaje, incluso cuando no hay trabajo para todos o el mismo es de pésima calidad.

Si se piensa en términos de agentes, o sea con capacidad de agencia, surge la pregunta acerca de cómo es ejercida la función pública por quienes trabajan en la intervención social dirigida a la población más desfavorecida, en tanto las precarias posibilidades de movilidad social se hacen muy evidentes. Surgen preguntas del tipo: cuál es el nivel de confianza que tienen sobre su tarea y qué implicancias tiene en las formas de ocupar el Estado ${ }^{1}$. Se puede aventurar que un énfasis en la integración social puede reafirmar la necesidad de un Estado fuerte, con funcionarios comprometidos y responsables en llevar adelante de forma adecuada su tarea. En tanto un énfasis en la subordinación, entendida como una injusticia, genera condiciones para una desconfianza hacia el Estado, complejiza las posibilidades de dar un sentido positivo a la tarea y no favorece una actitud hacia el cumplimiento de los mandatos institucionales.

Este trabajo surge de una actividad reflexiva, que se encuadra en una línea de investigación dirigida a estudiar las formas de habitar el Estado, en el ejercicio de la intervención social en las políticas asistenciales focalizadas en la pobreza y extrema pobreza. A modo de ensayo,

1 Iamamoto (1996, p. 186), al abordar esta discusión desde la crítica marxista la presenta como dos comportamientos frente a la tarea profesional del Trabajo Social: el fatalismo o el mesianismo utópico. 
se busca iluminar esta discusión a partir de algunos aportes clásicos de la filosofía política. Poder pensar el Estado para pensar el trabajo de los funcionarios que llevan adelante la intervención social, al considerarlo del lado bueno y del lado malo de las cosas, del lado de la integración social y política de una comunidad, y del lado de la subordinación y dominación de unos sobre otros.

Sobre las formas de habitar el Estado, poniendo la mirada en la Argentina del siglo XXI, Abad y Cantarelli (2010) señalan lo problemático que es, para los agentes estatales, ocupar el espacio estatal, cuando el mismo ha perdido legitimidad. Advierten que se asiste a una época aestatal, que deriva de la pérdida de la centralidad del Estado frente al mercado (consumidores vs. ciudadanos), el desprestigio de la política y el debilitamiento de las identidades político-partidarias. Para estos autores, que colocan al Estado del lado bueno de las cosas, la tensión que se genera al ocupar el Estado desde subjetividades a-estatales tiene implicancias en la integración social y política de la comunidad, o sea en la capacidad del Estado de construir un universal político.

Sin pretender abarcar todas las posibles formas subjetivas de ocupar el Estado, identifican tres tipos de subjetividades a-estatales (Abad y Cantarelli, 2010, pp. 45-60): El "héroe resistente", en este caso, sería una subjetividad heredada de la época de la dictadura de los 70 y 80 , cuando la actitud es de resistencia a la "opresión estatal", pero que en estos tiempos deriva hacia un defensor de la diversidad y las minorías. El principal problema lo encuentran en una reivindicación de las diferentes particularidades que no logran articularse en una unidad política. En segundo lugar, identifican al "yuppie estatal". Se trata de una subjetividad heredera del modelo de empresa que le impuso el neoliberalismo a la administración pública en los años 90. Aquí la dificultad radica en que los problemas del Estado son tratados como problemas técnicos, en clave de administración de una empresa privada, y el principio político de lo común queda subordinado a la eficacia y eficiencia, en particular en el presupuesto. En este esquema, la política nada tiene que hacer en la administración del Estado, a no ser representar un gasto. Por último, se encuentra la subjetividad que denominan "asambleísta deliberativo", desarrollada como consecuencia de sucesivas crisis económicas y políticas en la Argentina, que consolidaron una serie de discursos que hacen del Estado y los partidos políticos el foco de su 
crítica y denuncia. Por un lado, interpelando la autoridad estatal y, por otro, como respuesta, organizando espacios deliberativos y consultivos. El problema que identifican aquí es el nivel de escala, en el que pequeñas asambleas, sin representación, no tienen forma de constituirse en voluntad política popular común.

Para estos autores, se vuelve necesario generar las condiciones para una subjetividad capaz de habitar el Estado, algo que incumbe a una responsabilidad ético-política capaz de producir y sostener lo común: “...ocupar ese territorio es, para nosotros, significar un espacio de tal modo que se genere un mundo de símbolos, una pertinencia de la tarea, un proyecto y una forma de convivir con los compañeros y con las normas" (Abad y Cantarelli, 2010, p. 61). De lo contrario, lo que hay es un mundo falto de sentido, que genera malestar en el agente porque, precisamente, desprecia el lugar que le toca habitar. Además, atenta contra las posibilidades de promover una ética de la responsabilidad, que evite ser un "moralismo crítico" a-estatal o una "resistencia" al Estado, pero que asuma la tarea, incluso así sea para transformarla, teniendo presente lo social común como el espacio que hace posible la articulación de las diferentes demandas particulares. Porque, en la mirada de estos autores, el Estado es el territorio de los proyectos políticoinstitucionales que hacen a lo común.

\section{El Estado del lado de las cosas no tan malas}

La reflexión de Abad y Cantarelli se apoya en dos clásicos de la filosofía política: Hobbes, al que citan explícitamente al hablar de la representación (lo que presentan como "máscara estatal"), y Hegel que, si bien no figura explícitamente en el texto, siempre es posible encontrarlo entre líneas. Ambos autores presentan, cada uno desde su punto de vista, cuáles serían las buenas razones para estar juntos y darnos una forma de gobierno común.

El libro Leviatán de Hobbes es publicado por primera vez en 1651. En este tratado político, la razón para que los hombres² estén juntos es proteger su propia vida. Señala que todos los hombres son iguales por

2 Cuando se trabaja con textos de tanta antigüedad queda pendiente la duda sobre el alcance en la integración de la categoría "hombres". En todo caso, para esta exposición se considerará que integra todo el género humano. 
naturaleza y que es precisamente esa igualdad la fuente de todos los conflictos. En primer lugar, porque que los hombres sean iguales por naturaleza no quiere decir que compartan sus valoraciones sobre lo bueno y lo malo, eso es algo subjetivo de cada individuo aislado. Además, los hombres poseen un incesante afán de poder (riquezas, honor, placeres, entre otros) que los empuja a la competencia, la enemistad y la guerra entre ellos. Se genera así un contexto en el que tanto la propiedad como la vida de cada persona se encuentra constantemente amenazada. Por tanto, a los efectos de lograr la tranquilidad y de salvaguardar la vida, se vuelve racional sacrificar la libertad individual y someterse a un poder común que proteja a todos. Este poder común es el Estado, ya sea entendido como una monarquía, una aristocracia o una democracia. Para Hobbes lo que es importante, y que lo encuentra en estas tres formas de gobierno, es que la figura del soberano debe contener todo el poder. Solo una autoridad capaz de inspirar terror es capaz de lograr la paz social.

El poder soberano no es tan gravoso como la necesidad de él, y el daño deriva casi siempre de la escasa disposición a admitir uno pequeño. Puede objetarse aquí que la condición de los súbditos es muy miserable, puesto que están sujetos a los caprichos y otras irregulares pasiones de aquel o aquellos cuyas manos tienen tan ilimitado poder. Por lo común quienes viven sometidos a un monarca piensan que es, éste, un defecto de la monarquía, y los que viven bajo un gobierno democrático o de otra asamblea soberana atribuyen todos los inconvenientes a esa forma de gobierno. En realidad, el poder, en todas sus formas, si es bastante perfecto para protegerlos, es el mismo. Considérese que la condición del hombre nunca puede verse libre de una u otra incomodidad, y que lo más grande que en cualquiera forma de gobierno puede suceder, posiblemente, al pueblo en general, apenas es sensible si se compara con las miserias y horribles calamidades que acompañan a una guerra civil, o a esa disoluta condición de los hombres desenfrenados, sin sujeción a leyes y a un poder coercitivo que trabe sus manos, apartándoles de la rapiña y de la venganza. (Hobbes, 1980, cap. XVIII) ${ }^{3}$.

3 Sobre las citas al Leviatán de Hobbes y Filosofía del Derecho de Hegel, ambos libros se organizan por pequeñas secciones (capítulos en el Leviatán y $\S$ en Filosofía del Derecho) que ordenan los argumentos y conclusiones de los autores. En tanto son obras con variadas ediciones, se creyó mejor citar estas secciones en lugar del número de página. 
La posibilidad de lograr este contrato social, este acuerdo generalizado de transferir el derecho a la libertad a un soberano, se logra gracias a algunas pasiones que se encuentran en la naturaleza de las personas: "el temor a la muerte, el deseo de las cosas que son necesarias para una vida confortable, y la esperanza de obtenerlas por medio del trabajo" (cap. XI). Lo que Hobbes argumenta es, como por medio de la razón se hace evidente la necesidad de renunciar a este afán de poder y libertad sobre todas las cosas para lograr la paz, de aquí que "la justicia y la propiedad comienzan con la constitución del Estado" (cap. XV).

Por lo tanto, se encuentra una comunidad de hombres iguales en tanto su naturaleza que, por temor a la muerte y en búsqueda de su seguridad, aceptan las desigualdades que instalan las leyes civiles instrumentadas por el Estado. Y es razonable que sea aceptado, porque el Estado los cuida a todos. Hobbes dirá que "obedecer es honrar, porque ningún hombre obedece a quién no puede ayudarle o perjudicarle" (cap. X). El poder es sinónimo de honor porque, además de inspirar terror, permite ayudar a otros. O sea, el poder es legítimo en cuanto es ventajoso, incluso en la subordinación, y esto a tal punto que entiende que no se puede obligar a una persona a obedecer cuando su cuerpo o su vida está en riesgo. El cuidado de la propia vida como pilar de la razón del Estado se observa en el capítulo XXVII, en el que indica que no se puede castigar a quien cometiese un delito debido al "terror de la muerte inminente", lo que incluye la necesidad de alimentarse.

Cuando un hombre está desprovisto de alimento o de otra cosa necesaria para su vida, y no puede protegerse a sí mismo de ningún otro modo sino realizando algún acto contra la ley, como, por ejemplo, cuando en períodos de gran escasez toma el alimento por la fuerza, o roba lo que no puede obtener por dinero o por caridad, o en defensa de su vida arrebata la espada de manos de otro hombre, queda totalmente eximido por la razón que antes alegamos. (cap. XXVII).

Por lo que, si bien es un Estado que coarta libertades y que con sus leyes civiles (arbitrarias del soberano) genera desigualdad frente a una igualdad natural de todos los hombres, debe asegurar la subsistencia de todos los súbditos. Para este autor, la distribución de los bienes, de lo que es "mío, tuyo y suyo", es según lo juzgue el soberano, buscando la equidad y el bien común (cap. XXIV). 
En este esquema, los funcionarios del Estado son representantes del soberano. Para Hobbes, una persona "es aquel cuyas palabras o acciones son consideradas o como suyas propias, o como representando las palabras o acciones de otro hombre" (cap. XVI). Representar al soberano es asumir sus palabras, "actuar" en su nombre. Y quien viola la ley, en tanto ley de un soberano, no le hace daño a un particular sino al soberano, o sea al Estado mismo. Ser "actores del soberano" es ser la encarnación de lo que une a la sociedad, una "persona artificial", dirá Hobbes, en tanto actúan en representación de otro. Sobre esta idea es que Abad y Cantarelli argumentan que, para intervenir sobre una sociedad fragmentada, se necesita una acción estatal que articule y cree el lazo social. Y, para ello, es necesaria "una forma pública de comportamiento" que se base en un "hablar y actuar en forma responsable" que llamarán "máscara estatal". Para los autores, esta ficción y convención colectiva genera las condiciones para habitar el Estado. "Portar la máscara de agente estatal es ocupar un espacio de modo singular: no como vecino, no como contribuyente, no como patrón, no como amigo. Al permitirnos poner entre paréntesis nuestras palabras y acciones privadas, la máscara es la forma en la que se hace visible la unidad del modo de ser estatal" (Abad y Cantarerlli, 2010, p. 107).

Para Hegel la razón para pertenecer a una comunidad no puede ser condenarse a la servidumbre. Por el contrario, en su obra Filosofía del Derecho (FD), publicada por primera vez en 1821, señala que no hay un sometimiento de las personas al Estado, sino que este mismo es la realización de la posibilidad de ser personas libres. Y esto, al igual que con Hobbes, también es el resultado del uso de la razón. Hegel va a plantear que del contrato social que propone Hobbes, de una ley represiva y amenazante para contener a unos y otros, gracias al uso de la razón se pasa a un encuentro positivo con los otros. Ya no se hace lo correcto por temor a la muerte o el castigo, sino que se acepta hacer el bien aunque implique un sacrificio personal.

Es necesario exponer, así sea brevemente, algunas de las premisas que están en la base del método filosófico desarrollado por Hegel. Parte de un sujeto que reflexiona, que se piensa a sí mismo, y que al reflexionar también se transforma a sí mismo. Hay un movimiento circular entre la idea y lo real a través del cual el hombre, al ir reflexionando, se va dando forma a sí mismo. Y este movimiento circular es dialéctico, lo 
que quiere decir que avanza por medio de negaciones, de rupturas, de quiebres, que son superados en un estadio superior. Todo lo que nace lo hace para morir, ya trae consigo las propias contradicciones que van a determinar la necesidad de su superación. Pero también contiene el germen de su superación, que se encuentra en la idea, "primero aparece lo ideal frente a lo real en la madurez de la realidad, y después él crea a este mismo mundo, gestado en su sustancia, en forma de reino intelectual" (Hegel, 1968, p. 37). O sea, una vez realizada la realidad surge la reflexión, y una vez que aparece la idea por medio de la reflexión le da forma al mundo real. Y si la idea es producto de la razón y lo real es transformado por la idea, se llega a que "lo que es racional es real; y lo que es real es racional" (p. 34). Hay un movimiento teleológico de la historia guiado por la razón.

$\mathrm{Y}_{i}$ cuál es la idea que se gesta en la sustancia para crear el mundo real? Pues bien, la voluntad libre ( $\$ 21)$. El movimiento de la historia que llamará universal-, estudiado por medio de la dialéctica, le permite observar cómo el hombre, en su voluntad de ser reconocido y ser libre, se va encontrando con otras personas y, a medida que enfrenta y resuelve los problemas de la vida con otros, que se reconoce y los reconoce, avanza hacia concretar la idea. Este movimiento comienza con la propiedad como exterioridad de la libertad individual (\$41), que cuando se encuentra con otros necesita del contrato como reconocimiento de las diferentes libertades individuales. El contrato deviene en moralidad al reconocerse en una voluntad subjetiva común (\$105), y del contrato se pasa a la ética, como instancia más elevada en la que se reconocen la libertad individual y general (\$142). Este movimiento tiene su reflejo en lo real, pasando de la familia a la sociedad civil y, por último, al Estado. La familia como el primer grupo al que se pertenece y que brinda una identidad; la sociedad civil como esfera en la que se reconoce la individualidad de cada persona y la interdependencia de unos con otros para satisfacer sus necesidades (por medio del trabajo; en tanto el Estado es “la realidad de la idea ética” ( $\$ 257)$.

El Estado es la realidad de la libertad concreta; la libertad concreta, empero, consiste en el hecho de que la individualidad personal y sus intereses particulares tienen, tanto su pleno desenvolvimiento y reconocimiento de su derecho por sí (en el sistema de la familia y de la Sociedad Civil), cuanto, por una parte, se cambian por sí mismos 
en el interés de lo universal, y, por otra, con el saber y la voluntad la admiten como su particular espíritu sustancial y son aptas para él como su fin último. De modo que ni lo universal tiene valor y es llevado a cabo, sin el interés, el saber y el querer particular, ni los individuos viven como personas privadas meramente para esto, sin que, a la vez, quieran en y para lo universal y tengan una actividad consciente en este fin. $(\$ 260)^{4}$

El Estado se presenta como la comunidad jurídica en la que se realiza la idea ética, en la que los intereses individuales y generales están relacionados. La Constitución y la división de poderes que instituye para el gobierno son la "racionalidad desplegada y racionalizada" (\$265).

Hegel comparte con Hobbes que las diferentes formas de gobierno que se han dado los Estados (monárquico, aristocrático o democrático) no son más que variantes históricas de la realización de la idea ( 273 ) y que, en todos los casos, la unidad del Estado se representa en un individuo (\$279).

La esfera de la sociedad civil se constituye por una necesaria interdependencia de las personas para satisfacer sus necesidades por medio de su trabajo y el trabajo de los otros. Y esta interdependencia transforma el egoísmo subjetivo en cooperación (\$199), aunque se reconoce una desigualdad natural en la posibilidad de participar en la riqueza, debido a las diferentes destrezas y la base de capital (\$200). Y si bien la administración de la justicia viene a proteger la ofensa a la personalidad y a la propiedad, lo que verdaderamente interesa es que “...la garantía de la subsistencia y del bienestar del individuo, esto es, el bienestar particular, sea tratado y realizado como derecho" (\$230). Es a la administración pública, lo que Hegel llama policía (\$231), a quien corresponde la organización exterior de la Sociedad Civil, a efectos de garantizar y armonizar los diferentes fines e intereses particulares. Además de la libertad del comercio y de la industria, también se debe garantizar la protección del trabajo (\$236).

Y así como las personas adquieren derechos, también tienen obligaciones (§238), como por ejemplo su capacitación para el trabajo.

4 En todas las citas las cursivas corresponden al texto original. 
Pero si circunstancias accidentales, que exceden a la responsabilidad individual, impiden aprovechar de las ventajas de la sociedad civil para satisfacer sus necesidades y llevan a la pobreza: "El poder general toma el puesto de la familia para con los pobres, tanto respecto a su carencia inmediata, como respecto al sentimiento de aversión al trabajo, a la perversidad y a los otros vicios que provienen de tal situación y del sentimiento del propio error" (\$241).

Como se observa, la pobreza se registra como un problema material pero también moral que se debe atender, llevando socorro a los pobres en ambos sentidos. Incluso Hegel reconoce el problema de la acumulación de la riqueza (\$243) en una parte de la población y que lleva al empobrecimiento de otra y genera "la plebe" (\$244). Sin embargo, no ve adecuado que se imponga impuestos a los ricos para atender a la plebe, puesto que desestimula el trabajo, fundamento de la sociedad civil y de la autonomía y dignidad de las personas (\$245). Lo que se debe buscar es el reconocimiento y no la desvalorización de las personas. Frente a una industria en desarrollo, que no lograba integrar a todas las personas, la solución que propone pasa por medio de la ampliación del comercio con otros pueblos para hacer crecer la industria ( $\$ 246)$ y por la corporación ( $\$ 250)$, la clase de los artesanos, que actúa como una "segunda familia", al brindar trabajo y cuidar a sus miembros. Y este cuidado es una forma de reconocimiento, al ser la persona integrada a una organización por medio de su trabajo.

Sin ser miembro de una corporación legítima (y sólo en cuanto legítima, una comunidad es corporación), el individuo, sin dignidad de clase, está reducido desde su aislamiento al aspecto egoísta de la industria, a una cosa que no garantiza enteramente su subsistencia y aprovechamiento. (\$253)

En la corporación el apoyo que la pobreza recibe pierde su accidentalidad, así como su carácter humillante como injusticia; y la riqueza, en su obligación hacia su corporación, pierde el orgullo y la envidia que pueden suscitarse, aquél en sus posesores y ésta en los demás; es decir, que la honradez obtiene su verdadero reconocimiento y su verdadera dignidad. (\$253)

En relación con los agentes encargados de llevar adelante las decisiones, en particular de la policía, que es lo que aquí interesa, tienen 
como fin sostener el interés general del Estado, a diferencia de los intereses de la sociedad civil, que son los privados y particulares (\$289). Los mismos conforman "la clase media, que alberga la inteligencia culta y la conciencia jurídica de la masa de un pueblo" (\$297). El servicio público implica el abandono de los intereses subjetivos, a no ser que los mismos se encuentren en el cumplimiento del deber. De hecho, tener como función hacer valer lo universal protege al funcionario de las arbitrariedades de los gobernantes (\$294). Y, en relación con la conducta de los funcionarios, la misma estaría asegurada por una "formación ética" y por la "grandeza del Estado", que debilita los vínculos e intereses privados (\$296). Además, el riesgo de los desvíos en la conducta en la función pública se encuentra doblemente controlado. Por encima por los gobernantes y por debajo desde la sociedad civil con sus corporaciones. Ambos, por sus intereses, que también son parte del desarrollo de la idea, velan porque esta clase media cumpla adecuadamente su función.

\section{El Estado del lado de las cosas no tan buenas}

Sin lugar a dudas, la principal referencia a la crítica al Estado como algo justo y necesario se encuentra en Marx. Entre sus artículos sobre el robo de leña en los bosques, publicados en la Gaceta Renana en 1842 (Marx, 1983, pp. 204-244) y su Crítica de la filosofía del derecho de Hegel (Marx, 2010), cuya introducción fue publicada en los Anales franco alemanes en 1844 y el resto de la obra en forma póstuma, se puede observar cómo evoluciona su reflexión en torno al Estado.

En los artículos sobre el robo de leña muestra su indignación frente a la injusticia que comete la Dieta Renana cuando, en nombre del Derecho, en lugar de defender la res pública (la cosa pública), antepone el interés privado de los propietarios de los bosques. Es interesante observar cómo Marx muestra aún cierta confianza en la forma en que "debería" funcionar el Estado y el Derecho en defensa de la libertad de todos ciudadanos. Históricamente los pobres han recogido leña del suelo de los bosques para la calefacción y cocción de alimentos. Pero, con el desarrollo de la industria, la fuerte demanda del carbón y el proceso de mercantilización de la vida que desarrollaba el capitalismo emergente, la Dieta Renana promueve una ley para castigar el robo de leña seca, caída de los árboles, e incluso obligar al ladrón a devolver lo robado así sea con trabajo. 
En esos artículos señala cómo, en el proceso de transformación del régimen feudal al Estado moderno, no logra instalarse un trato hacia todos los hombres como ciudadanos libres e iguales. Al convertirse la propiedad feudal en propiedad privada, mantiene los privilegios de sus propietarios y, sin embargo, deja en peor situación a quienes, siendo la clase desposeída, ahora además pierden la posibilidad de recoger leña y frutos del bosque para su subsistencia. En la Edad Media la propiedad tenía un "carácter fluctuante, que no hacía de ella con claridad una propiedad privada, pero tampoco con claridad una propiedad pública, una mezcla de derecho privado y público" (Marx, 1983, p. 213) que, al transformarse solo en propiedad privada, niega la situación de los pobres, quedando a la deriva frente a una sociedad civil que no les garantiza un lugar. Y, con la ley del robo de leña, se agrega lo que entiende una "ilegítima persecución judicial".

La pena no debe causar mayor horror que la contravención, la ignominia del delito no debe transformarse en ignominia de la ley; se socava el terreno del Estado cuando la desdicha se convierte en delito o el delito en desdicha. Muy alejada de esta perspectiva, la Dieta ni siquiera observa las primeras reglas de la legislación. (Marx, 1983, p. 216)

En estos artículos registra cómo el Estado sacrifica sus propios intereses al hacer suyos los intereses de la propiedad privada, el interés de los particulares, en circunstancias que el interés del Estado debería basarse en el desinterés o en el interés general. Y este contraste lo registra claramente, cuando la Dieta Renana adjudica responsabilidad de aplicar la ley a los guardias forestales contratados por los propietarios de los bosques. Se les asigna la responsabilidad de cuidar y juzgar el castigo sobre el robo de leña a quien está al servicio del interés privado.

El interés no piensa, calcula. Los motivos son sus números. El motivo es un móvil para eliminar las razones jurídicas, y ¿quién duda de que el interés privado tendrá a este respecto muchos móviles? La bondad del motivo consiste en la casual ductilidad con la que es capaz de apartar la situación objetiva y adormecerse a sí mismo y a los demás en el engaño de que no es la cosa misma lo que hay que pensar sino que respecto de una cosa mala basta con el buen pensamiento. (Marx, 1983, p. 231) 
Este cuestionamiento a la Dieta Renana, como formando parte de un Estado imperfecto, prontamente derivará en su crítica al Estado burgués en la obra Crítica a la filosofía del derecho de Hegel (Marx, 2010). En su introducción comienza señalando cómo la filosofía alemana de la época da por finalizada la crítica de la religión, al tomar a esta por un producto del hombre; sin embargo, identifica que la justificación del Estado realizada por Hegel viene a reemplazar la idea religiosa por la idea ética. No es la idea la que moldea al hombre y hace que su historia lo lleve a la conformación del Estado, sino que son los hombres los que hacen al Estado.

La religión es la interpretación general de este mundo, su resumen enciclopédico, su lógica en forma popular, su point d'honneur espiritualista, su exaltación, su sanción moral, su solemne complemento, su consuelo y justificación universal. Es la realización fantástica del ser humano, porque el ser humano no tiene una verdadera realidad. La guerra contra la religión es, entonces, directamente, la lucha contra aquel mundo, cuyo aroma moral es la religión. (p. 7)

El centro de su crítica es que Hegel, más que explicar el desarrollo histórico de los Estados, realiza una descripción del Estado monárquico tal y como existía en Prusia en ese momento. Al partir del Estado como realización de la idea, el resto de la fundamentación opera como una justificación de la sociedad alemana de 1820. Por lo tanto, Marx dirá que el razonamiento se encuentra invertido, en tanto Hegel, "en vez de desarrollar su pensamiento partiendo del objeto, desarrolla el objeto a partir de un pensamiento consumado, que ya ha resuelto sus problemas en el abstracto ámbito de la «lógica»" (p. 80). No se trata de una fundamentación lógica del Estado, sino de un Estado que fundamenta la lógica (p. 84).

Hegel desarrolla al Estado político (realización de la idea ética) como una esfera diferente de la sociedad burguesa (sociedad civil) y la familia. El Estado político se presenta como una forma organizadora de la comunidad. Sin embargo, para Marx el hecho de que sea una esfera diferente da cuenta de cómo un particular impone sus intereses como universales al asumir la representación del todo. "La Constitución ha sido hasta ahora el ámbito religioso, la religión de la vida del pueblo, el cielo de su generalidad frente a la existencia terrena de su realidad" (p. 102). 
El Estado moderno, tal y como se conoce, es el Estado burgués que, en nombre del interés general, defiende el interés particular. Es interesante observar cómo, en esta obra, sustituye el término "sociedad civil" por el de "sociedad burguesa", incluso cuando discute el concepto de Hegel: "La corporación es el intento de la sociedad burguesa por convertirse en Estado; pero la burocracia es el Estado que realmente se ha convertido en la sociedad burguesa" (Ibíd.). El Estado, lejos de ser la realización de la idea de libertad, en realidad se presenta como la sociedad burguesa jurídicamente garantizada y, con ello, la reproducción de sus desigualdades.

Desde esta mirada, la crítica a la investidura ética de los burócratas presenta una relación análoga con la crítica a la investidura religiosa como manto espiritual que cubre lo real. "El espíritu burocrático es un espíritu jesuítico y teológico a más no poder. Los burócratas son los jesuitas y teólogos del Estado. La burocracia es la république prêtre" (p. 120). Los burócratas son los encargados de llevar adelante la administración y, por lo tanto, la reproducción de la sociedad burguesa. Para ello hacen de los fines formales del Estado (ideas de libertad) su propio fin, pero inevitablemente entran en conflicto con los fines reales de la sociedad burguesa:

Por tanto, se ve obligada a pasar lo formal por el contenido y al contenido por lo formal. Los fines del Estado se convierten en fines de oficina o los de oficina en fines del Estado. La burocracia es un círculo del que nadie puede escapar. Su jerarquía es una jerarquía del saber. La cúspide confía a los círculos inferiores el conocimiento de lo singular, mientras que los círculos inferiores confían a la cúspide el conocimiento de lo general; y así se engañan mutuamente". (Ibíd.)

Y en esta explicación revertida, la actitud ética del burócrata, de la que nos habla Hegel, su espiritualidad, deviene en materialismo. Por un lado, presenta un interés objetivo por el que el burócrata hace del fin del Estado su propio fin, a través de ocupar un puesto, un sueldo, en un ascenso, etc. Pero también es una materialidad subjetiva, "en cuanto la vida se convierte en objeto de despachar burocráticamente" (p. 121).

Así como la burocracia es por una parte este craso materialismo, por la otra se muestra su craso espiritualismo en que quiere hacerlo 
todo, es decir, que para ella la voluntad es la causa prima. Actitud lógica desde el momento en que no es más que existencia activa, cuyo contenido recibe de fuera; solo dando forma y limitando este contenido puede demostrar la propia existencia. El mundo no es para el burócrata sino objeto de despacho. (Ibíd.)

En este trabajo, Marx también va a contraponer al Estado burgués con lo que llama la "democracia verdadera". Con ello refiere a una forma de organización que parte del demos total y no se diferencia en una esfera particular (el Estado político). Siguiendo esta idea y a partir de la frase "los franceses modernos lo han interpretado en el sentido de que el Estado político tiene que desaparecer en la verdadera democracia; interpretación correcta, en cuanto el Estado, como Estado político, como Constitución, deja de valer por el todo" (p. 100), Abensour encuentra en Marx, además de su materialismo, una indagación en la filosofía política que califica de "momento maquiaveliano", al identificar una alternativa en la política para lograr la emancipación (Abensour, 1998). Por ello, ve necesario diferenciar en Marx la crítica al Estado político de la política. De ahí que encuentra en la "verdadera democracia" una oposición al Estado político, una democracia que evita la reificación en cualquier tipo de dogmatismo. $\mathrm{Y}$ esto porque es una democracia que parte del demos y no de la idea, como en Hegel. Su fundamento es la libertad del hombre real. Para ello, el Estado político debe ser reducido al reconocimiento de lo que es, un momento en la existencia del pueblo, una forma particular de organizarse. Reducido a lo que es, la democracia quitaría el velo de la sobresignificación que envuelve al Estado como forma organizadora. "En síntesis: la verdadera democracia podría definirse como un estado de adecuación entre el pueblo y sus objetivaciones tan perfecto que hiciera desaparecer el riesgo de una precipitación en alienación" (p. 104).

La conclusión a la que llega Abensour es que antes que tomar el poder del Estado hay que oponerse a él. Se trata de acabar con el Estado político, que ejerce su dominación como parte de un todo. Y que esto es posible por medio de la democracia en tanto que, cuanto más se acerca a su verdad, más se interpela el poder arbitrario del Estado que se enmascara en su autonomización. Y lo mismo al revés, donde el Estado se hace fuerte representa una amenaza para la democracia, en tanto implica concentración del poder (p. 127). Su propuesta pasa por 
“una transformación del poder en potencia para actuar en común, o, si se prefiere, un pasaje del poder sobre al poder con los hombres y entre los hombres, siendo el entre el lugar donde se conquista la posibilidad de un mundo común" (pp. 128-9). Desde la democracia se debe denunciar el poder del Estado para ubicarlo en el sitio que le corresponde, evitar la absolutización de las formas cuando estas mantienen una distancia entre una justicia social y material (p. 130).

Sobre como se logra el conformismo social, necesario para la reproducción del orden social, Gramsci (1980) reflexiona en torno a la tarea educativa que se desarrolla desde el Estado y la sociedad civil. El Estado, a través del Derecho y de sus instituciones, como la escuela, reproducen un tipo de sociedad y una forma de relacionarse entre las personas. Lo que se transmite son las formas de ser y relacionarse de la clase dominante, y esto a través de un equilibrio entre estrategias coercitivas, de compensación y de persuasión. Un ejemplo claro es cómo el Derecho se impone suponiendo la libre aceptación de sus normas, dando por normal el mundo que instituye. Pero la tarea educativa no es solo desde el aparato público; también se ponen en juego actividades culturales y políticas privadas que responden a la clase dominante. "El Estado tiene y pide el consenso, pero también lo «educa» por medio de las asociaciones política y sindicales, que son sin embargo organismos privados, dejados a la iniciativa privada de la clase dirigente" (p. 155).

En realidad, lo que se encuentra en Gramsci es una noción de "Estado" no restringida a lo gubernativo. La noción de "hegemonía" que utiliza, convoca a considerar cómo la sociedad civil y la sociedad política se entrelazan en lo que se entiende por "Estado". La educación del pueblo, bajo la hegemonía de la clase dominante, tiene un efecto de naturalizar las normas al punto de que sean aceptadas sin resistencias, al quedar escondida su arbitrariedad. Y si esta enseñanza del ser de la clase dominante llegase a encontrar resistencia, tiene a su disposición una variedad de mecanismos coercitivos. En este caso, la burocracia y los burócratas representan "la cristalización del personal dirigente" al servicio de la reproducción de la hegemonía.

\section{Sobre las formas de habitar el Estado}

Muchos años han pasado desde la publicación de estos textos y el Estado ya no es el mismo. En particular y en lo que atañe a este trabajo, 
se destaca el desarrollo de la cuestión social y sus diferentes respuestas por parte de la seguridad social y de la asistencia social.

Se puede relacionar la acción del Estado, como generador y administrador de la vida en común, y la profesión del Trabajo Social con el estudio realizado por Dubet (2006) acerca del trabajo sobre los otros, entendido como un trabajo de socialización que media entre valores universales y los individuos particulares, orientado a inculcar normas que, al mismo tiempo que configuran al individuo, lo vuelven "libre" y autónomo, y que quienes lo llevan adelante lo hacen por vocación, en tanto se funda en transmitir valores. La acción del Estado, por medio de la política social y la política asistencial, implica algo más que la materialidad que se transfiere en recursos o servicios, también implica un sujeto a socializar. Pero Dubet encuentra que este programa institucional entró en crisis en las últimas décadas del siglo XX, porque "los valores perdieron su unidad; la vocación choca contra los requerimientos de eficacia profesional, contra los constreñimientos de organizaciones más lábiles y más complejas, y la creencia entre una continuidad entre socialización y subjetivación ya no resulta tan evidente" (p. 23). Este planteo de crisis, frente al desarme de la idea de una sociedad sostenida por valores comunes, es también lo que identifican Abad y Cantarelli (2010) como base de la dificultad para habitar el Estado, y la necesidad de desarrollar una ética estatal con capacidad de promover un universal político.

Los autores abordados en este ensayo consideran al Estado como un universal político, lo que habilita la reflexión acerca de las implicancias sobre una ética estatal en el desempeño de la tarea de los agentes de la intervención social.

Con Hobbes se encuentran las razones más conservadoras y autoritarias para la justificación de un Estado mínimo, que interviene por medio de la represión y la asistencia social. Recuérdese que, para Hobbes, hay buenas razones para obedecer y aceptar las desigualdades que instalan las leyes civiles, en tanto se castiga, pero también se ayuda. El Estado se justifica en la necesidad de imponer orden por medio del miedo y el respeto a la autoridad. En este caso, la pérdida de centralidad del Estado o el declive del programa institucional se explica por la falta de una autoridad, que no logra imponer la unidad, que deja a los hombres "desenfrenados y sin sujeción a las leyes y a un poder 
coercitivo que trabe sus manos" en su afán de poder y riquezas. Aquí la función de los agentes de la intervención social es principalmente normativa y de control social. Son los representantes del Estado en sus acciones y palabras y, como tales, son la encarnación de lo que une a la sociedad por medio del temor y respeto que infunda la autoridad del Estado.

Con Hegel el papel del Estado y de los agentes de la intervención social adquiere una mirada mucho más virtuosa. Ya no se trata de anteponer la autoridad a la libertad, sino que es la propia idea de libertad la que da la forma al Estado, quien representa la comunidad jurídicamente organizada. Que el Estado sea "la realidad de la idea ética" implica que toda su institucionalidad es creada en relación dialéctica con la imagen de la idea. El Estado es un universal que incluye los diferentes particulares, lo que necesariamente le demanda intervenir en la armonización de los diferentes intereses presentes en la sociedad civil. Entre estos, responder a los problemas - materiales y morales- que se generan a partir de la desigualdad como resultado de la competencia económica. En Hegel no se trata solo de llevar asistencia, sino que hay una preocupación por el reconocimiento de todos los individuos como miembros útiles de la comunidad. Preocupación que se puede trasladar, hoy en día, a los efectos estigmatizantes de la política asistencial focalizada en la pobreza.

En un ejercicio de reflexión, se puede relacionar la concepción del Estado de Hegel, en la cual la comunidad organizada es ahora en una escala continental o planetaria, al desarrollo del enfoque de derechos en las políticas sociales y asistenciales promocionado por la CEPAL en América Latina (por ejemplo, Sepúlveda 2014). A partir del reconocimiento por parte de los Estados de los derechos económicos, sociales y culturales, este enfoque se propone velar por su cumplimiento, identificando dónde se violenta la normativa. Esta mirada busca trascender la obligación legal en sus pretensiones, también agrega el objetivo de servir de orientación normativa a los efectos de universalizar el acceso al bienestar. Se puede decir que, bregar por el cumplimiento de los derechos es poner en acción la realización de la idea. De aquí que el agente de la intervención sea considerado alguien que se despoja de sus intereses particulares y orienta sus acciones a los intereses universales por medio de la promoción de los derechos. 
En el caso del marxismo el Estado es interpelado en sus intenciones, en tanto es una institución que se encarga de imponer un particular como universal. Al constituirse el capitalismo sobre una relación de explotación, no hay lugar en el Estado burgués para una transformación que implique un cambio en dicha relación. Por ello, el método ya no parte de la idea, sino de las relaciones sociales de producción que dejan en evidencia las contradicciones del capitalismo.

En este caso, los burócratas son considerados como teólogos del Estado, condicionados por su lugar de asalariados en la administración. Gramsci retoma esta mirada desde el rol educativo y promotor en la reproducción de las relaciones sociales burguesas. El Estado pide y educa en consenso, que convierte en un sentido común que esconde la arbitrariedad de las desigualdades.

Esta crítica al burócrata como teólogo de la burguesía bien podría aplicarse al ejemplo del enfoque de derechos propuesto por la CEPAL. Sin embargo, el desarrollo del pensamiento marxista dentro del trabajo social ha dado lugar a una dimensión ético-política de la profesión, que también implica la "defensa intransigente de los derechos humanos" (Iamamoto, 1998, p. 170) en el ejercicio profesional. En este caso, no se trata de una esperanza puesta en un régimen jurídico, sino que busca actuar conociendo y visibilizando sus verdaderas intenciones. Para ello se propone un análisis crítico del lugar ocupado por el trabajador social como asalariado en la división sociotécnica del trabajo en el tratamiento de la cuestión social. Lugar que lo ubica cerca de las necesidades para la subsistencia de los sectores trabajadores y sus demandas frente a la clase capitalista. Al respecto, Iamamoto dirá

...se trata de una competencia crítica capaz de descifrar la génesis de los procesos sociales, sus desigualdades y las estrategias de acción para enfrentarlas. Supone competencia teórica y fidelidad al movimiento de la realidad; competencia técnica y ético-política que subordine el "cómo hacer" al "qué hacer" y éste al "deber ser", sin perder de vista sus raíces en el proceso social (p. 100).

Este proyecto ético-político promueve la ampliación de la democracia y la ciudadanía, buscando defender las conquistas del trabajo frente al capital, al mismo tiempo que se promueven nuevos derechos. También implica un llamado a la recuperación de la esfera de lo públi- 
co, ampliando la -verdadera - participación de la población e involucrándola en los temas que le conciernen. Es una apuesta a disputar el sentido común hegemónico en el campo de la política social y asistencial, a partir de aprovechar el lugar estratégico que ocupa el ejercicio profesional en el tratamiento de la cuestión social. Y esto sin desconocer la tensión entre el proyecto profesional y el lugar de asalariado y las funciones asignadas. En este caso, no hay una posibilidad de construir un proyecto ético de lo común desde el Estado. Aquí la referencia es a un proyecto ético-político, que se construye en forma contra hegemónica a las formas de dominación del capital y al reconocimiento del Estado como institución puesta a su servicio.

\section{Reflexiones finales}

Este ensayo comenzó con la interrogante sobre las implicancias que tiene para los agentes estatales el ocupar su espacio cuando se ubica al Estado del lado bueno o del lado malo de las cosas. En el repaso realizado, se da cuenta de que la comunidad política es algo más que la sociedad civil y, también, que la sociedad civil no siempre tiene la capacidad de integrar a todos los miembros de la comunidad política. De ahí la importante función del aparato burocrático del Estado en no ser solamente una mera administración, sino en su capacidad de generar diferentes mecanismos de integración social. Algunos de los textos trabajados pertenecen a una época en la que los Estados no habían desarrollado su cara social; sin embargo, sus reflexiones sobre los fines del Estado y el lugar que ocupan sus burócratas son útiles, aunque, paradójicamente, el tipo de tarea sobre la que se quiere reflexionar rara vez se realiza desde un escritorio.

Si la mirada se posiciona en la integración social, se reconoce que la misma es tanto material como moral. La intervención del Estado no solo es una ayuda material para permitir la subsistencia, también y particularmente es un reconocimiento de pertenecer a una comunidad política. "Respeto", "honor", "reconocimiento" son palabras cargadas de mucho significado y que alertan acerca de que la intervención social no debe convertirse en la instalación de un estigma. Sin embargo, la mirada puesta en la subordinación acusa a la moral de la integración de falsa conciencia, de favorecer la reproducción de una comunidad política que, en su base, está atravesada por la injusticia. Esto abre 
una interrogante en cuanto cómo se articulan los intereses subjetivos y la ética política en los agentes del Estado. Así sea que ubiquen al Estado del lado de las cosas no tan buenas o no tan malas, si son meros operadores o ejercen su capacidad de agencia, al reinterpretar y no siempre obedecer los mandatos institucionales, ya sea por convicción o por conveniencia.

Como se dijo al principio, toda integración es integración en la subordinación: la subordinación a las normas hegemónicas de la comunidad política, sean las que sean. Y, en general, implica el reconocimiento de diferencias, desigualdades, de unos que están más cómodos que otros. Pero lo que interpela es cuál es el nivel de diferencias y relaciones de subordinación tolerables en una comunidad de iguales. O sea, cuánto se puede ser igual en tanto persona si no se es igual en el reconocimiento y condiciones materiales. Y esto atraviesa la intervención social que se realiza desde el Estado. Si hay diferencias legítimas, aunque no reconocidas explícitamente, no se oficia el mismo trato a todos, aspecto que trasciende la propia objetividad de la política y se transfiere también a las relaciones cotidianas. En todo caso, se entiende que en la forma que se han ido configurando los Estados modernos, en su accionar se ponen en juego tanto la integración social como la subordinación. Lo que deja la pregunta para ser respondida por medio de la investigación empírica sobre cómo los agentes de la intervención social resuelven y fundamentan su trabajo en esta tensión.

\section{Bibliografía}

Abad, S. y Cantarelli, M. (2010). Habitar el Estado. Pensamiento estatal en tiempos a-estatales. Buenos Aires: Hydra.

Abensour, M. (1998). La democracia contra el Estado. Buenos Aires: Colihue.

Castel, R. (2004). La inseguridad social ¿Qué es estar protegido? Buenos Aires: Manantial.

Donzelot, J. (2007). La invención de lo social. Ensayo sobre la declinación de las pasiones políticas. Buenos Aires: Nueva Visión.

Dubet, F. (2006). El declive de la institución. Profesionales, sujetos e individuos en la modernidad. España: Gedisa.

Gramsci, A. (1980). Notas sobre Maquiavelo, sobre la politica y sobre el Estado moderno. Madrid: Nueva Visión. 
Hegel, G. F. (1968). Filosofía del Derecho. Buenos Aires: Claridad.

Hobbes, T. (1980). Leviatán. Madrid: Editora Nacional.

Iamamoto, M. V. (1992). Servicio social y división del trabajo. Sao Paulo: Cortéz.

Iamamoto, M. V. (1998). El servicio social en la contemporaneidad. Trabajo y formación profesional. Biblioteca latinoamericana de servicio social. Sao Paulo: Cortéz.

Marx, K. (1983). En defensa de la libertad. Los artículos de la Gaceta Renana 1842-1843. Valencia: Fernando Torres-Editor.

Marx, K. (2010). Crítica de la filosofía del Estado de Hegel. Madrid: Biblioteca Nueva.

Rinesi, E. (2020) Clase 3. Texto elaborado para el Seminario de Filosofía Política del Doctorado en Trabajo Social de la Facultad de Trabajo Social de la Universidad Nacional de La Plata, Argentina. Inédito.

Sepúlveda, M. (2014). De la retórica a la práctica: el enfoque de derechos en la protección social en América Latina. Serie Políticas Sociales, (189), CEPAL. Santiago de Chile. 